\title{
VIOLÊNCIA, PAZ E DIREITOS HUMANOS: CHAMADA À AÇÃO
}

GOMES, Candido Alberto; NASCIMENTO, Grasiele Augusta Ferreira;

KOEHLER, Sônia Maria Ferreira (Org.). Culturas de violência, culturas de paz:

da reflexão à ação de educadores, operadores do direito e

defensores dos direitos humanos. Curitiba: CRV, 2012, 341 p.

A luta pela superação das violências não é nova na história da humanidade. Todavia, nos dias atuais, a discussão desse fenômeno envolve enfaticamente a temática dos direitos humanos por eles serem violados. Cultura de violência, cultura de paz: da reflexão à ação de educadores, operadores do direito e defensores dos direitos humanos é fruto de seminário internacional com pesquisadores dedicados há bastante tempo ao assunto. O livro, com sua dinâmica interdisciplinar, correspondente à complexidade dos desafios, alerta os seus leitores que as mudanças da realidade dependem, até certo ponto, de cada um de nós, que podemos dar sentido às recomendações de pesquisas, colocar em prática observações de estudiosos da área e contribuir para fazer valer as políticas públicas e a lei. Constitui, pois, uma chamada individual, familiar, civil, social e profissional à ética, ao compromisso social e à ação, necessários à superação das violências e ao respeito aos direitos humanos.

A obra, organizada em três partes, relata constatações científicas e analisa normas jurídicas sem exigir do leitor conhecimentos prévios de direito. Reúne ao todo 15 capítulos, em português e espanhol, de autoria de pesquisadores e profissionais de diferentes áreas (educação, sociologia, filosofia, psicologia e direito), que, de suas perspectivas, abordam a complexidade do tema, compartilhando experiências que convidam o leitor, em suas possibilidades, a fazer diferença em face 
das violências que impedem a efetivação plena dos direitos humanos, inerentes à dignidade humana. Embora a obra tenha como eixo condutor os direitos humanos, a educação - escolar e também extraescolar - é aspecto explorado do início ao fim. Com caráter formativo já a partir do prefácio do representante da Unesco no Brasil, Lucien André Muñoz, a obra constitui significativo momento de instrução a seus leitores de diferentes áreas do conhecimento e campos de atividades. É um momento de reflexão necessária aos educadores, uma vez que enfatiza o papel do docente na formação de crianças, adolescentes e jovens.

Na primeira parte, “Jovem, violência e cenários: a educação na escola e além da escola”, busca-se definir a adolescência de perspectivas sociológicas pouco exploradas, com suas mudanças, diferentes interpretações e as dinâmicas interpessoais dos que são os alunos. Sete artigos destacam a função da escola e dos educadores, que vai além do ensino dos conteúdos, até porque moral, ética e cidadania não são espontâneas, são aprendidas. Educadores, inclusive pelo exemplo, podem conduzir os estudantes a uma convivência mais humana, pautada no diálogo e ainda ajudá-los a construir relações de respeito ao se conscientizarem dos seus atos. Educadores podem especialmente preparar os estudantes a se reconhecer como pessoas com direitos e deveres. No entanto, chama-se a atenção para o comprometimento de todos os envolvidos - os pais e/ou responsáveis, a comunidade - nesse processo.

Os capítulos salientam a importância de uma educação mais humanista nos tempos atuais, isto é, o desafio que se coloca aos educadores de conhecer seus estudantes como pessoas, respeitá-los e promover a convivência humana, mediando os conflitos entre eles de modo a levá-los a reconhecer a necessidade de respeito à pessoa humana, cujas diferenças não param de crescer, sem tempo para processos de assimilação, como há um século. Não por acaso, resultados de pesquisas revelam uma relação desgastada entre alunos e professores, que acaba por agravar ainda mais as violências e infringir os direitos humanos. Em síntese, fica evidenciada a importância da formação docente, a associação da escola e da família além da união de diferentes profissionais, todos responsáveis direta ou e indiretamente pelo bem-estar social, para lidar com o fenômeno das violências - abordado na obra por um prisma multifacetado e interdisciplinar. Nesta primeira parte do livro se analisam, entre outros temas, as relações entre o luto e as violências nas escolas, em inovadora abordagem tanatológica: a necessidade do melhor conhecimento do aluno (esse mesmo que hoje sai inesperadamente às ruas para protestar) e das suas redes de relações e a construção da moralidade e a formação de sujeitos éticos.

Em geral, a escola é vista como uma minissociedade onde os estudantes aprendem a conviver com suas diversidades e preferências. Para tanto, é preciso que ela, num processo contínuo de escuta e 
avaliação, repense suas práticas para superar o modelo autoritário que perdura por séculos. Assim, nos faz examinar a necessidade de repensar tanto a educação básica como a superior que, além de habilitarem com instrumental técnico, precisam cultivar alternativas de ações sociais éticas e responsáveis além de enfatizar as implicações políticas da atuação humana. Com isso, se poderá romper com uma visão cindida da realidade, desenvolvendo nos indivíduos o senso do coletivo, do conjunto, da interação e da percepção única de pertença para com a sociedade.

A segunda parte da obra, intitulada "Direitos humanos: para que a corda não arrebente sempre do lado mais fraco", provê embasamento teórico e empírico acerca dos direitos humanos, destacando os grupos mais vulneráveis, isto é, mulheres, crianças e adolescentes que têm seus direitos violados e sua dignidade ferida. Também são focalizados como vítimas não apenas os oprimidos, mas também os oprimidos opressores, que submetem e são submetidos, exploram e são explorados, provocam e sofrem a dor e, portanto, precisam ser igualmente cuidados. Entre outros pontos, destaca-se que a busca da paz tem constituído um desejo utópico, uma vez que a violência enquanto enigma constitutivo da realidade humana continua em discussão. Problematiza-se o tema direitos humanos a partir das políticas públicas contemporâneas, em especial aquelas relativas às drogas, à sexualidade e ao tráfico de crianças e adolescentes no Brasil, que, por sua vez, manifestam a necessidade de outras formas de organização e funcionamento distantes da burocracia clássica. Alerta-se, desse modo, que políticas públicas frágeis e insuficientes acentuam ainda mais os direitos de cidadania dos ricos em detrimento dos pobres. A superação da violência implica, portanto, o respeito à dignidade de todos e à de cada "ser", merecedores que são de indistinta consideração do Estado, da sociedade, das coletividades, dos grupos, da família, da escola e da pessoa, singularmente considerada, razão pela qual é do interesse de todos.

Em suma, busca-se esclarecer não só a arquitetura dos direitos humanos. Os direitos são também exercícios que se traduzem em políticas públicas, de modo que sempre devem estar a serviço da escola, da justiça ou das empresas, constituindo-se como saberes promotores de direitos humanos - o que implica discussões acerca da ética e o compromisso social.

À luz da contemporaneidade, discutem-se as práticas do bullying e cyberbullying, chagas das relações sociais, manifestadas principalmente (mas não só) nas escolas, que maculam a dignidade da condição humana e violam a ordem jurídica, precisando, pois, ser melhor estudadas, compreendidas e superadas pela sociedade contemporânea e seus personagens em prol da dignidade da pessoa humana. Nesta segunda parte, ainda é frisado que parte dos problemas que vivemos hoje decorre das profundas mudanças culturais que acabam por se constituir em desafios à escola. Portanto, questionam-se os efeitos da modernidade, 
apontando as consequências cegas dessa modernidade, ao mesmo tempo em que são feitas críticas ao Brasil, que aparentemente se mostra um país liberal, embora sua cultura midiática muitas vezes se traduza em desrespeito aos direitos humanos mais elementares. Dessa forma, põe-se em relevo a não efetividade da lei, que acaba por favorecer mais a delinquência e a transgressão do que os valores éticos e sociais.

Alguns autores reconhecem ter havido um avanço no combate ao tráfico de crianças e adolescentes para fins de exploração sexual; entretanto, a realidade evidencia que ainda há muito para ser conquistado, também em relação ao combate à violência sexual, cujas modalidades continuam rapidamente se alastrando devido à ineficiência das leis, ao descaso da sociedade, imbuída de preconceitos diversos, e a uma cultura machista.

O livro se organiza metaforicamente como um rio que desemboca na última parte, "Rumo às soluções” (não que antes não se tenha tratado do assunto), tecendo as contribuições ao longo da obra e aprofundando a aplicação dos conhecimentos às ações. Os dois artigos que a compõem explicitam a complexidade das violências, destacando a fragilidade e as limitações da escola e alertando que não se pode esperar que ela resolva todos os problemas quando não tem recebido apoio para isso. Dela só se pode esperar aquilo que faz parte das suas funções e possibilidades, sem lhe atribuir a missão de milagreira, capaz de resolver os problemas sociais e até econômicos. Em vez disso, a complexidade dos problemas requer o engajamento de todos os setores da sociedade, missão difícil, porém mais viável do que enganosamente lançar sobre as costas da escola o que não lhe compete. No entanto, é necessário um conjunto de medidas para que esta possa alcançar suas finalidades e objetivos, o que envolve formação adequada de educadores, reestruturação do seu espaço físico, responsabilização dos pais, legislação pertinente etc. Tudo isso só será possível quando a educação passar a ser, no caso brasileiro, uma prioridade verdadeira e não meramente declaratória. Assim, a escola, não raro palco e autora de violências, é vítima também do descaso e, por isso, não pode sozinha se responsabilizar pelas respostas que dá - ou não - aos seus problemas, o que facilita jogos de empurra. Aliás, propagar a escola como panaceia e/ou anatematizar suas múltiplas omissões tem um papel ideológico que não é inédito nem circunscrito ao Brasil.

O último capítulo, cujo título é “Chegando à foz do rio”, retoma os principais aspectos de cada um dos capítulos anteriores e contribuições dos coautores para refletir sobre a temática das violências, sobre as quais, apesar dos longos anos de investigação, tão pouco ainda sabemos. Nesse sentido, salienta que a academia precisa não só desenvolver investigações científicas inter/transdisciplinares, de modo a buscar e debater soluções, mas também propor políticas públicas integradas. Assim, ao mesmo tempo em que lhe compete disseminar seus saberes, necessita propor alternativas e políticas para resolver os problemas, focalizando 
o que fazemos com o que sabemos. Com espírito humanístico, resgata a nossa capacidade de sonhar, "não sonhos inalcançáveis, pois, na qualidade de educadores, formamos pessoas e, queiramos ou não, somos exemplos e fontes de inspiração, sejam quais forem eles”. Finaliza com foco no valor da educação e de suas potencialidades para focalizar os direitos humanos quando todos nós, inevitavelmente, dependemos uns dos outros para viver com ética e exemplo de modo a colocá-los em prática.

Trata-se, pois, de uma obra com posições enriquecedoramente plurais, que dialoga com outras obras também numa perspectiva interdisciplinar. O conjunto de referências, mesclando obras clássicas e contemporâneas em vários idiomas, constitui outro aporte relevante para os atores que desejam aprofundar os temas nos horizontes nacional e internacional. Uma obra para ser lida e recomendada pela urgência das questões em pauta.

\section{ADRIANA LIRA}

Mestre e doutoranda em Educação pela Universidade Católica de Brasília - UCB; professora adjunta e secretária executiva da Cátedra Unesco de Juventude, Educação e Sociedade na mesma Universidade adrianaliraucb@gmail.com 